\title{
LA UTILIDAD DE LOS CONOCIMIENTOS INÚTILES*
}

Abraham Flexner

"DOI: https://doi.org/10.18601/01245996.v22n42.03. Versión original: Abraham Flexner, The usefulness of useless knowledge, Harper's Magazine, octubre de 1939, pp. 544-552. Traducción de Alberto Supelano. Fecha de recepción: 07-02-2018, fecha de aceptación: 11-10-2019. Sugerencia de citación: Flexner, A. (2020). La utilidad de los conocimientos inútiles. Revista de Economía Institucional, 22(42), 49-63.

a Filósofo y educador estadounidense, fue uno de los fundadores del Instituto de Estudios Avanzados de Princeton. 


\section{La utilidad de los conocimientos inútiles}

Resumen. Abraham Flexner, promotor intelectual del Instituto de Estudios Avanzados de Princeton y quien fuera su director entre 1930 y 1939, publicó este escrito días después del inicio de la Segunda Guerra Mundial, cuando el odio irracional amenazaba a la civilización, así como la democracia hoy peligra bajo el impulso ultra racional de la utilidad inmediata. En este escrito Flexner señala que la vida intelectual y espiritual - propia de los centros donde se busca y se cultiva el conocimiento- es una forma inútil de actividad que brinda mayores satisfacciones de las que se obtendrían de otra manera. Y muestra que la búsqueda de tales satisfacciones es una fuente de utilidad inesperada. $\mathrm{El}$ autor argumenta que en la historia de la ciencia los grandes descubridores no han sido motivados por el deseo de ser útiles sino por el de satisfacer su curiosidad. Hoy, cuando la búsqueda de la utilidad práctica e inmediata goza de la más amplia aceptación, sigue siendo relevante preguntar si puede haber una vida plena si se siguen suprimiendo los elementos que le dan significado espiritual, y si nuestra concepción de lo que es útil no es aún más estrecha que en la época de Flexner. Aunque estas preguntas no figuren en la agenda de quienes trazan y siguen, consciente o inconscientemente, las actuales políticas educativas y científicas.

Palabras clave: historia de la ciencia; JEL: B10

\section{The usefulness of useless knowledge}

Abstrac. Abraham Flexner, intellectual promoter of the Institute of Advanced Studies of Princeton and who was its director between 1930 and 1939, published this writing days after the start of World War II, when irrational hatred threatened civilization, as democracy threatens today under the ultra rational impulse of immediate utility. In this paper Flexner points out that the intellectual and spiritual life - appropriate of the centers where knowledge is sought and cultivated - is a useless form of activity that provides greater satisfactions than they would otherwise obtain. And it shows that the search for stories satisfactions is an unexpected source of utility. The author argues that in the history of science the great discoverers have not been motivated by the desire to be useful but to satisfy their curiosity. Today, when the search for practical and immediate utility enjoys the widest acceptance, it is still relevant to ask if you can have a full life if you continue to suppress the elements that give it spiritual meaning, and if our conception of what is useful does not It is even narrower than in the Flexner era. Although these questions do not appear on the agenda of those who trace and follow, consciously or unconsciously, current educational and scientific policies.

Keywords: history of Science; JEL: B10

\section{A utilidade do conhecimento inútil}

Resumo. Abraham Flexner, promotor intelectual do Instituto de Estudos Avançados de Princeton e que foi seu diretor entre 1930 e 1939, publicou este artigo dias após o início da Segunda Guerra Mundial, quando o ódio irracional ameaçou a civilização, como a democracia ameaça hoje sob a lógica ultra-racional. impulso de utilidade imediata. Neste artigo, Flexner salienta que a vida intelectual e espiritual - apropriada dos centros onde o conhecimento é procurado e cultivado - é uma forma inútil de atividade que fornece maiores satisfações do que elas obteriam. E mostra que a busca por satisfação de histórias é uma fonte inesperada de utilidade. $\mathrm{O}$ autor argumenta que na história da ciência os grandes descobridores não foram motivados pelo desejo de serem úteis, mas de satisfazer sua curiosidade. Hoje, quando a busca por utilidade prática e imediata desfruta de uma aceitação mais ampla, ainda é relevante perguntar se você pode ter uma vida plena se continuar suprimindo os elementos que lhe dão significado espiritual e se nossa concepção do que é útil é útil. Não é ainda mais estreito do que na era Flexner. Embora essas questões não apareçam na agenda de quem rastreia e segue, consciente ou inconscientemente, as atuais políticas educacionais e científicas.

Palavras-chave: história da ciência; JEL: B10 
¿No es curioso que en un mundo lleno de odios irracionales que amenazan a la civilización, hombres y mujeres -viejos y jóvenes- se alejen del todo o en parte de la enojosa corriente de la vida cotidiana para dedicarse a cultivar la belleza, ampliar el conocimiento, curar enfermedades, aliviar el sufrimiento, como si en forma simultánea los fanáticos no se dedicaran a sembrar dolor, fealdad y sufrimiento? El mundo ha sido siempre un lugar confuso y desalentador; sin embargo, los poetas, artistas y científicos han ignorado los factores que, de prestarles atención, los habrían paralizado. Desde el punto de vista práctico, la vida intelectual y espiritual es, a primera vista, una forma inútil de actividad a la que se entrega la gente porque le brinda mayores satisfacciones de las que obtendría de otra manera. En este escrito examinaré hasta qué punto la búsqueda de esas satisfacciones inútiles resulta ser, en forma inesperada, la fuente de una utilidad jamás soñada.

Oímos decir, en forma reiterada y fastidiosa, que la nuestra es una época materialista, cuya principal preocupación debería ser una distribución más amplia de los bienes y las oportunidades materiales. La protesta justificada de quienes, sin culpa alguna, son privados de oportunidades y de una parte justa de los bienes materiales desvía a un creciente número de jóvenes de los estudios que siguieron sus padres hacia el estudio, igualmente importante y no menos urgente, de los problemas sociales, económicos y gubernamentales. Nada tengo contra esta tendencia. El mundo en el que vivimos es el único del que pueden ser testigos nuestros sentidos. Salvo que hagamos un mundo mejor y más justo, millones de personas seguirán yendo a la tumba en silencio, tristes y llenas de amargura. He dedicado muchos años a argumentar que nuestras escuelas deberían ser más conscientes del mundo en que sus alumnos y estudiantes están destinados a vivir. Aunque a veces me pregunto si esa tendencia no es demasiado fuerte y si habría suficientes oportunidades para una vida plena si se suprimiesen del mundo algunas de las cosas inútiles que le dan significado espiritual. En otras palabras, si nuestra concepción de lo que es útil no se ha vuelto demasiado estrecha para adecuarse a las posibilidades errantes y caprichosas del espíritu humano.

Podemos considerar esta pregunta desde dos puntos de vista: el científico y el humanista o espiritual. Empecemos por el científico. Recuerdo una conversación que tuve hace unos años con George Eastman sobre el tema de la utilidad. Eastman, un hombre sensato, 
gentil y perspicaz, de buen gusto musical y artístico, me había dicho que pensaba dedicar su enorme fortuna a promover la educación en temas útiles. Me atreví a preguntarle a quién consideraba el científico más útil del mundo. Al instante respondió: "Marconi". Lo sorprendí al decirle: "Cualquiera que sea el placer que obtengamos de la radio y pese a que la comunicación inalámbrica y la radio han aportado a la vida humana, la contribución de Marconi fue casi insignificante".

No olvidaré su estupor. Me pidió que se lo explicara. Le respondí más o menos así:

Señor Eastman, Marconi era inevitable. El crédito real por todo lo que se ha hecho en el campo de la comunicación inalámbrica pertenece, si ese crédito fundamental se puede atribuir a alguien, al profesor Clerk Maxwell, quien en 1865 hizo ciertos cálculos abstrusos y remotos en el campo del magnetismo y la electricidad. Maxwell reprodujo sus ecuaciones abstractas en un tratado que publicó en 1873. En la siguiente reunión de la Asociación Británica, el profesor H. J. S. Smith de Oxford declaró: "ningún matemático puede leer las páginas de estos volúmenes sin darse cuenta de que contienen una teoría que hace un gran aporte a los métodos y recursos de las matemáticas puras”. Otros descubrimientos realizados en los quince años siguientes complementaron el trabajo teórico de Maxwell. Finalmente, en 1887 y 1888 el problema científico aún pendiente -la detección y la demostración de las ondas electromagnéticas portadoras de señales inalámbricas- fue resuelto por Heinrich Hertz, quien trabajaba en el laboratorio de Helmholtz en Berlín. Ni a Maxwell ni a Hertz les preocupaba la utilidad de su trabajo; esa idea jamás les paso por la mente. No tenían ningún objetivo práctico. E1 inventor, en sentido legal, fue sin duda Marconi, pero ¿qué inventó Marconi? El último detalle técnico, principalmente el dispositivo receptor hoy obsoleto llamado cohesor, descartado casi universalmente.

Hertz y Maxwell nada inventaron, pero su inútil trabajo teórico fue aprovechado por un técnico brillante y creó nuevos medios de comunicación, de servicio público y de entretenimiento mediante los cuales hombres con méritos relativamente menores ganaron fama y millones. ¿Quiénes fueron los hombres útiles? No fue Marconi, fueron Clerk Maxwell y Heinrich Hertz. Hertz y Maxwell eran genios sin pensar en la utilidad. Marconi fue un hábil brillante sin otro pensamiento que la utilidad.

La mención de Hertz recordó a Eastman las ondas hertzianas, y le sugerí que preguntara a los físicos de la Universidad de Rochester que habían hecho exactamente Hertz y Maxwell. Y le dije una cosa de la que podía estar seguro: que habían hecho su trabajo sin pensar en la utilidad y que a lo largo de la historia de la ciencia la mayoría de 
los descubrimientos realmente grandes, que al final habían resultado beneficiosos para la humanidad, se debían a hombres y mujeres que no estaban impulsados por el deseo de ser útiles sino por el simple deseo de satisfacer su curiosidad.

¿Curiosidad?, preguntó Eastman.

Sí, le respondí, la curiosidad que puede resultar o no en algo útil es quizá la característica más destacada del pensamiento moderno. No es nueva. Se remonta a Galileo, Bacon y sir Isaac Newton, y no se le debe poner ningún obstáculo. Las instituciones de enseñanza deberían dedicarse a cultivar la curiosidad y cuanto menos se desvíen por consideraciones de utilidad inmediata, más probable es que contribuyan no solo al bienestar humano sino a la igualmente importante satisfacción del interés intelectual, el cual se ha convertido en la pasión dominante de la vida intelectual en los tiempos modernos.

II

Lo que es cierto de Heinrich Hertz, quien trabajó en silencio e inadvertido en un rincón del laboratorio de Helmholtz durante los últimos años del siglo XIX, también se puede decir de científicos y matemáticos de todo el mundo de siglos anteriores. Vivimos en un mundo que estaría desamparado sin electricidad. Si tuviéramos que mencionar el descubrimiento de uso práctico más inmediato y de mayor alcance, quizá coincidiríamos en mencionar la electricidad.Pero ¿quién hizo los descubrimientos fundamentales de los que proviene el desarrollo eléctrico observado durante más de un siglo?

La respuesta es interesante. El padre de Michael Faraday era herrero; Michael fue aprendiz de encuadernador. En 1812, cuando tenía veintiún años, un amigo lo llevó a la Royal Institution, donde escuchó cuatro conferencias de sir Humphrey Davy sobre temas químicos. Faraday tomó notas y envió una copia a Davy. En el año siguiente, en 1813, se convirtió en asistente de laboratorio de Davy y trabajó en problemas químicos. Dos años después acompañó a Davy en un viaje al continente. En 1825, cuando tenía treinta y cuatro años, se convirtió en director del laboratorio de la Royal Institution, donde pasó cincuenta y cuatro años de su vida.

E1 interés de Faraday pronto pasó de la química a la electricidad y el magnetismo, a los que dedicó el resto de su vida activa. Oersted, Ampère y Wollaston ya habían hecho un trabajo importante pero desconcertante en este campo. Faraday aclaró las dificultades que ellos no habían resuelto y en 1841 logró inducir la corriente eléctri- 
ca. Cuatro años después se abrió una segunda e igualmente brillante época de su carrera, cuando descubrió el efecto del magnetismo sobre la luz polarizada. Sus primeros descubrimientos han llevado al infinito número de aplicaciones prácticas mediante las cuales la electricidad ha aliviado las cargas y ampliado las oportunidades de la vida moderna. Hasta ahora, sus descubrimientos posteriores han sido menos prolíficos en resultados prácticos. ¿Qué influencia tuvo esto en Faraday? Ninguna. La utilidad no le interesó en ningún periodo de su inigualable carrera. Se dedicó a desenmarañar los enigmas del Universo; al inicio, enigmas químicos; en periodos posteriores, enigmas físicos. En lo que a él le importaba, jamás se planteó la cuestión de la utilidad. Cualquier sospecha de aplicación práctica habría limitado su inagotable curiosidad. Al final, hubo utilidad, pero nunca fue el criterio al que sometiera su incesante experimentación.

En la atmósfera que envuelve al mundo de hoy quizá sea oportuno enfatizar que el papel que cumplió la ciencia para hacer más destructiva y más horrible la guerra fue un subproducto inconsciente e indeseado de la actividad científica. Lord Rayleigh, presidente de la Asociación Británica pare el Avance de la Ciencia, en un discurso reciente mostró en detalle que la locura humana, no la voluntad de los científicos, es responsable del uso destructivo de los agentes empleados en la guerra moderna. El estudio inocente de la química de los compuestos de carbono, que ha tenido infinitos resultados benéficos, mostró que la acción del ácido nítrico sobre sustancias como el benceno, la glicerina, la celulosa, etc., no solo resultaba en la benéfica industria del colorante de anilina sino en la creación de la nitroglicerina, que tiene usos buenos y malos. Poco después, Alfred Nobel, volviendo al mismo tema, mostró que al mezclar nitroglicerina con otras sustancias se podían producir explosivos sólidos manejables con seguridad, como la dinamita. A la dinamita le debemos el progreso en la minería, en la perforación de túneles de ferrocarril como los que hoy atraviesan los Alpes y otras cadenas montañosas; pero, por supuesto, los políticos y militares han abusado de ella. Sin embargo, los científicos no tienen más culpa de la que tienen un terremoto o una inundación. Eso mismo se puede decir del gas tóxico. Plinio murió por respirar dióxido de azufre en la erupción del Vesubio hace casi dos mil años. Los científicos no aislaron el cloro con fines bélicos, tampoco el gas mostaza. Estas sustancias de podrían limitar al uso benéfico, pero cuando se perfeccionó el avión, hombres de corazones envenenados y cerebros confundidos vieron que el avión, una invención inocente, resultado de un largo y desinteresado esfuerzo científico, se podía 
convertir en instrumento de destrucción, algo que nadie jamás había soñado ni buscado en forma deliberada.

En el dominio de las matemáticas superiores se pueden citar innumerables casos. Por ejemplo, la obra matemática más abstrusa de los siglos XVIII y XIX fue la "geometría no euclidiana". Su inventor, Gauss, aunque reconocido por sus contemporáneos como un matemático distinguido, no se atrevió a publicar su trabajo sobre ese tema durante un cuarto de siglo. La teoría de la relatividad, con sus infinitas aplicaciones prácticas, habría sido imposible sin la labor que Gauss realizó en Gotinga. Otro ejemplo, lo que hoy se conoce como "teoría de grupos" era una teoría matemática abstracta e inaplicable. La desarrollaron hombres curiosos a los que su curiosidad y su interés los condujeron a caminos extraños. Pero la "teoría de grupos" es hoy la base de la teoría cuántica de la espectroscopia, la cual utilizan diariamente personas que no saben cuál fue su origen.

Todo el cálculo de probabilidades fue descubierto por matemáticos cuyo interés real era racionalizar los juegos de azar. No ha cumplido el propósito práctico que buscaban, pero es la base científica de toda clase de seguros y de vastas ramas de la física del siglo XIX.

De un número reciente de Science, cito lo siguiente:

La estatura del genio del profesor Albert Einstein alcanzó nuevas alturas cuando se reveló que el erudito físico matemático hace quince años desarrolló las matemáticas que hoy ayudan a resolver los misterios de la sorprendente fluidez del helio a temperaturas cercanas al cero absoluto. En el simposio sobre acción intermolecular de la Sociedad Química Americana, el profesor F. London, de la Universidad de París, profesor visitante en la Universidad de Duke, dio al profesor Einstein el crédito por el concepto de gas "ideal” que expuso en escritos publicados en 1924 y 1925.

Los reportes de Einstein de 1925 no se referían a la teoría de la relatividad sino que discutían problemas sin ningún significado práctico en ese momento. Describían la degeneración de un gas "ideal” cerca de los límites inferiores de la escala de temperatura. Como sabían que todos los gases se tornan líquidos a esas temperaturas, los científicos pasaron por alto los trabajos realizados por Einstein hace quince años.

Sin embargo, el descubrimiento reciente del comportamiento del helio líquido ha dado nueva utilidad al olvidado concepto de Einstein. La mayoría de los líquidos son más viscosos, se vuelven más pegajosos y fluyen con menor facilidad cuando se enfrían. El dicho "más frío que la melaza en enero" expresa el concepto de viscosidad de la persona común, y es correcto.

E1 helio líquido, sin embargo, es una excepción desconcertante. A la temperatura conocida como "punto delta", solo 2,19 grados por encima del 
cero absoluto, el helio líquido fluye mejor que a temperaturas más altas y de hecho, es casi tan nebuloso como un gas. A este extraño comportamiento se suman otros enigmas, como su gran capacidad para conducir el calor. En el punto delta es unas 500 veces más efectivo a este respecto que el cobre a temperatura ambiente. E1 comportamiento del helio líquido, con estas y otras anomalías, es un gran misterio para los físicos y los químicos.

E1 profesor London afirmó que el comportamiento del helio líquido se puede explicar mejor considerándolo como un gas "ideal" de Bose-Einstein, usando las matemáticas elaboradas en 1924-1925 y asumiendo algunos de los conceptos de conducción eléctrica de los metales. Por simple analogía, la sorprendente fluidez del helio líquido se puede explicar en parte imaginando la fluidez como algo similar al movimiento aleatorio de los electrones en los metales para explicarla conducción de la electricidad.

Miremos ahora en otra dirección. En el dominio de la medicina y la salud pública, la ciencia de la bacteriología ha desempeñado un importante papel durante medio siglo. ¿Cuál es la historia? Al acabar la guerra franco-prusiana de 1870, el gobierno alemán fundó la gran Universidad de Estrasburgo. Su primer profesor de anatomía fue Wilhelm von Waldeyer, después profesor de esa materia en Berlín. En sus Reminiscencias relata que entre los estudiantes que asistían a la clase de primer semestre en Estrasburgo había un joven pequeño, discreto y autónomo, de 17 años, llamado Paul Ehrlich. En esa época, el curso usual de anatomía consistía en la disección y el examen microscópico de tejidos. Ehrlich mostró poca o ninguna atención a la disección, pero, como dice Waldeyer en sus Reminiscencias:

Muy pronto noté que Ehrlich trabajaba largas horas en su escritorio, totalmente absorto en la observación al microscopio. Además, su escritorio se fue cubriendo gradualmente con manchas de colores. Un día que lo vi sentado trabajando, me acerqué y le pregunté qué hacía con ese arcoiris de colores en su mesa. Entonces este joven estudiante de primer semestre que supuestamente seguía el curso regular de anatomía me miró y dijo en tono amable: "Ich probiere". Lo que se podría traducir libremente como "Estoy probando" o como "Solo estoy tanteando". Le respondí: "Muy bien. Siga tanteando". Vi enseguida que sin ninguna enseñanza o dirección de mi parte tenía en Ehrlich a un estudiante de inusual calidad.

Con prudencia, Waldeyer lo dejó solo. Ehrlich cursó precariamente las materias de medicina y al final obtuvo su título, sobre todo porque para sus profesores era obvio que no tenía intención de usarlo para ejercer la medicina. Después fue a Breslau, donde trabajó con el profesor Cohnheim, también maestro de nuestro doctor Welch, fundador y primer decano de la Escuela de Medicina Johns Hopkins. Creo que la 
idea de utilidad jamás cruzó por la mente de Ehrlich. Él tenía interés. Era curioso y siguió tanteando. Por supuesto, su tanteo era guiado por un profundo instinto, pero era una motivación puramente científica y no utilitaria. ¿Cuál fue el resultado? Koch y sus asociados establecieron una nueva ciencia, la ciencia de la bacteriología. Un compañero de estudios, Weigert, recurrió a los experimentos de Ehrlich para teñir bacterias y así ayudar a diferenciarlas. El mismo Ehrlich desarrolló la tinción de las muestras de sangre con las tinturas en las que se basa nuestro conocimiento actual de la morfología de los glóbulos rojos y blancos. No pasa un día sin que en miles de hospitales de todo el mundo se use la técnica de Ehrlich en el análisis de la sangre. Así, el tanteo aparentemente sin rumbo en la sala de disección de Waldeyer en Estrasburgo se convirtió en un importante factor en la práctica diaria de la medicina.

Ahora daré un ejemplo de la industria, seleccionado al azar, pues hay muchos más. El profesor Berl, del Instituto Carnegie de Tecnología (en Pittsburgh), dice lo siguiente:

E1 fundador de la industria moderna del rayón fue el conde francés Chardonnet. Se sabe que utilizaba una solución de nitrocelulosa en alcohol y éter, y que hacía pasar a presión esta solución viscosa a través de capilares en agua que servían para coagular el filamento de nitrato de celulosa. Después de la coagulación, el filamento se exponía al aire y se enrollaba en bobinas. Un día Chardonnet fue a inspeccionar su fábrica francesa en Besançon. Por accidente, cesó el suministro del agua que debía coagular el filamento de nitrato de celulosa. Los trabajadores descubrieron que la operación del hilado funcionaba mucho mejor sin agua que con ella. Ese día nació el importante proceso del hilado en seco, que hoy se emplea a gran escala.

No estoy sugiriendo que todo lo que se hace en los laboratorios finalmente tenga un uso práctico inesperado ni que el uso práctico final lo justifique. Más bien, abogo por la abolición del término "uso" y por la liberación del espíritu humano. Sin duda, así liberaremos algunos maniáticos inofensivos y desperdiciaremos algunos dólares preciosos. Pero lo que es infinitamente más importante es que romperemos los grilletes de la mente humana y la liberaremos para que se aventure por los caminos que, en nuestros días, han llevado a Hale, Rutherford, Einstein y sus semejantes a regiones del espacio alejadas de nosotros por millones y millones de kilómetros, y a liberar la ilimitada energía aprisionada en el átomo. Lo que Rutherford y otros, como Bohr y Millikan, han hecho por pura curiosidad, en su 
esfuerzo por entender la estructura del átomo, ha liberado fuerzas que pueden transformar la vida humana; pero este resultado práctico final, imprevisto e impredecible, no es una justificación del empeño de Rutherford, Einstein, Millikan, Bohr o de sus pares. Dejémoslos solos. Ningún administrador educativo puede decidir el camino que ellos han de recorrer. E1 desperdicio, lo admito de nuevo, parece enorme. En realidad, no lo es. Todo el desperdicio que se podría atribuir al desarrollo de la bacteriología es insignificante en comparación con las ventajas provenientes de los descubrimientos de Pasteur, Koch, Ehrlich, Theobald Smith y muchos otros; ventajas que jamás habrían surgido si la idea del uso posible arraigara en su mente. Estos grandes artistas -porque eso son los científicos y los bacteriólogos-difundieron el espíritu que prevalecía en los laboratorios en los que simplemente seguían el camino abierto por su propia curiosidad natural.

No critico instituciones como las escuelas de ingeniería o de derecho donde necesariamente predomina el criterio de la utilidad. No es raro que la situación se invierta, y que las dificultades prácticas que se encuentran en la industria o en los laboratorios alienten investigaciones teóricas que puedan o no resolver los problemas que las suscitaron, aunque abran nuevas perspectivas, inútiles en ese momento, pero preñadas de logros futuros, prácticos y teóricos.

Con la rápida acumulación de conocimiento "inútil" o teórico se ha creado una situación en la que hay cada vez más posibilidades de abordar problemas prácticos con un espíritu científico. No solo inventores, sino científicos "puros" se han dedicado a este deporte. Ya mencioné a Marconi, un inventor, que, aunque benefactor del género humano, se limitó de hecho a "cosechar el cerebro de otros hombres". Edison pertenece a esa misma categoría. Pasteur era diferente. Era un gran científico, pero no se negaba a abordar problemas prácticos, como la condición de las viñas francesas o los problemas de la elaboración de la cerveza. No solo resolvía la dificultad inmediata sino que del problema práctico también sacaba alguna conclusión teórica de gran alcance, "inútil" en ese momento pero, después, probablemente "útil" de un modo imprevisto. Erhlich, cuya curiosidad era básicamente especulativa, abordó enérgicamente el problema de la sífilis y prosiguió con tenacidad hasta que encontró una solución de uso práctico inmediato: la arsfenamina. Los descubrimientos de la insulina por Banting, para tratar la diabetes, y del extracto de hígado por Minot y Whipple, contra la anemia maligna, pertenecen a la misma categoría: ambos fueron realizados por científicos puros que percibieron que personas despreocupadas por su aplicación práctica habían acumu- 
lado mucho conocimiento "inútil", y pensaron que era el momento de hacer preguntas prácticas de manera científica.

Es obvio entonces que se debe ser cauteloso al atribuir el descubrimiento científico a una sola persona. Casi todos los descubrimientos tienen una historia larga e imprecisa. Alguien encuentra una pieza aquí y otro una pieza allá. Después se da un tercer paso y otros más, hasta que un genio junta las piezas y hace la contribución decisiva. La ciencia, como el río Misisipi, es al comienzo un riachuelo en un bosque distante. Otras corrientes aumentan gradualmente sus aguas. Y el río rugiente que rompe los diques está formado por numerosas fuentes.

No puedo tratar este aspecto en forma exhaustiva, pero puedo decir de pasada que durante uno o dos siglos la contribución de las escuelas profesionales a su actividad respectiva será, probablemente, no tanto la formación de personas que después se convertirán en ingenieros prácticos, abogados prácticos o médicos prácticos, sino en el hecho de que incluso en la búsqueda de objetivos estrictamente prácticos se mantendrá una gran cantidad de actividades en apariencia inútiles. De esa actividad inútil provienen descubrimientos que pueden resultar infinitamente más importantes para la mente y el espíritu humanos que el logro de los fines útiles para los que se fundaron esas escuelas.

Las consideraciones que he hecho subrayan -si fuese necesario subrayar- la enorme importancia de la libertad espiritual e intelectual. He hablado de ciencia experimental y de matemáticas; pero lo que digo es también cierto de la música, el arte y cualquier otra expresión del espíritu humano libre. El simple hecho de que brinden satisfacción a un alma individual que busca purificarse es toda la justificación que necesitan. Y al justificarse sin hacer referencia, implícita o actual, a la utilidad, justificamos las escuelas, las universidades y los institutos de investigación. Una institución educativa que libera generaciones sucesivas de almas humanas está plenamente justificada, bien sea que tal o cual graduado haga o no una contribución útil al conocimiento humano. Un poema, una sinfonía, una pintura, una verdad matemática, un nuevo hecho científico, todos ellos tienen en sí mismos todas las justificaciones que necesitan o requieren la universidades, las escuelas y los institutos de investigación.

$\mathrm{E} 1$ asunto que estoy discutiendo es hoy causa de peculiar conmoción. En grandes zonas del mundo -en especial en Alemania e Italia- se están haciendo esfuerzos para reprimir la libertad del espíritu humano. Se han reorganizado las universidades hasta convertirlas en instrumentos de quienes profesan un credo político, económico o racial particular. De vez en cuando un individuo irreflexivo de al- 
guna de las pocas democracias que quedan en el mundo cuestionará la importancia fundamental de que una libertad académica sin traba alguna. El verdadero enemigo de la especie humana no es el pensador audaz e irresponsable, tenga o no razón. El enemigo real es el que trata de moldear el espíritu humano para que no se atreva a extender sus alas, así como una vez se extendieron en Italia y Alemania, igual que en Gran Bretaña y Estados Unidos.

Esta no es una idea nueva. Fue la idea que animó a Humboldt cuando, en la hora de la conquista de Alemania por Napoleón, concibió y fundó la Universidad de Berlín. Es la idea que animó al presidente Gilman para fundar la Universidad Johns Hopkins, el modelo que han seguido en mayor o menor medida todas las universidades de este país para reformarse. Es la idea a la que será fiel todo individuo que valora su alma inmortal, sean cuales sean las consecuencias personales. Sin embargo, la justificación de la libertad espiritual va más allá de la creatividad en el campo de la ciencia o el humanismo, pues implica la tolerancia en toda la gama de las diferencias humanas. Frente a la historia de la especie humana, ¿qué puede ser más absurdo o ridículo que las simpatías o antipatías basadas en la raza o la religión? ¿La humanidad desea sinfonías, pinturas y verdades científicas profundas, o acaso desea sinfonías cristianas, pinturas cristianas y ciencia cristiana, o sinfonías judías, pinturas judías y ciencia judía; o contribuciones musulmanas, egipcias, japonesas, chinas, americanas, alemanas, rusas, comunistas o conservadoras a la infinita riqueza del alma humana que sean expresión del espíritu humano?

\section{IV}

Entre las consecuencias más llamativas e inmediatas de la intolerancia hacia los extranjeros puedo citar, quizá con justicia, el rápido desarrollo del Instituto de Estudios Avanzados, fundado en Princeton, Nueva Jersey, por Louis Bamberger y su hermana Caroline Bamberger Fuld. En 1930 se sugirió fundar el Instituto. Se ubicó en Princeton debido en parte al apego de sus fundadores al Estado de Nueva Jersey, pero, en lo que a mí concierne, porque Princeton tenía una pequeña escuela superior de alta calidad con la que era posible una colaboración más estrecha. El Instituto tiene con la Universidad de Princeton una deuda que nunca se podrá apreciar del todo. E1 trabajo del Instituto con gran parte de su personal empezó en 1933. En su profesorado figuran eminentes estudiosos estadounidenses: Veblen, Alexander y Morse entre los matemáticos; Meritt, Lowe y Miss Goldman entre 
los humanistas; Stewart, Riefler, Warren, Earle y Mitrany entre los publicistas y economistas. A ellos se deben añadir estudiosos y científicos de la misma talla que se congregaban en la Universidad, la biblioteca y los laboratorios de Princeton. Pero el Instituto de Estudios Avanzados está en deuda con Hitler por Einstein, Weyl y Neumann en matemáticas; por Herzfeld y Panofsky en el campo de los estudios humanísticos, y por una multitud de investigadores más jóvenes que en los últimos seis años han trabajado bajo la influencia de este distinguido grupo y han fortalecido la academia estadounidense en todo el país.

Desde el punto de vista organizativo, el Instituto es lo más simple y menos formal que se pueda imaginar. Tiene tres escuelas: una Escuela de Matemáticas, una Escuela de Estudios Humanísticos y una Escuela de Economía y Política. Cada escuela está formada por un grupo permanente de profesores y un grupo de miembros asociados que cambia cada año. Cada escuela dirige sus propios asuntos como le place y dentro de cada grupo cada individuo dispone de su tiempo y su energía también como le place. Los miembros asociados, que han llegado ya de veintidós países y de treinta y nueve instituciones de estudios superiores de Estados Unidos, son admitidos, según sus méritos, por los diversos grupos. Disfrutan de la misma libertad que los profesores. Pueden trabajar con uno u otro profesor tal como acuerden; pueden trabajar solos, consultando de vez en cuando a quien consideren conveniente. No se sigue ninguna rutina; no se hacen distinciones entre profesores, asociados e invitados. Los estudiantes y profesores de Princeton y los asociados y profesores del Instituto se mezclan con tanta libertad que son indistinguibles. Se cultiva el estudio como tal. Los resultados para el individuo y la sociedad se dejan en sus propias manos. No hay reuniones de profesores y no existen comités. Así, los individuos con ideas tienen condiciones favorables para la reflexión y el diálogo. Un matemático puede cultivar las matemáticas sin distracciones, un humanista cultivar su campo, y un economista o un estudiante de ciencias políticas el suyo. La administración se ha reducido al mínimo en extensión e importancia. Los individuos sin ideas, sin capacidad para concentrarse en las ideas, no se sentirían a gusto en el Instituto.

Quizá pueda aclarar este punto mencionando brevemente algunos ejemplos. Un profesor de Harvard al que se le dio una beca para venir a Princeton escribió preguntando:

$-¿$ ¿Cuáles son mis deberes?

-Le respondí no tiene obligaciones; solo oportunidades. 
Un matemático joven y capaz que pasó un año en Princeton vino a despedirse. A punto de irse comentó:

-Quizá le gustaría saber qué ha significado este año para mí.

-Sí-respondí.

-Las matemáticas - me dijo con un tono enérgico- avanzan rápidamente; la literatura actual es extensa. Hace más de diez años que me doctoré. Durante un tiempo pude mantenerme al día en mi tema; pero últimamente eso se ha vuelto cada vez más difícil e incierto. Hoy, después de un año aquí, las persianas se levantaron, la habitación está iluminada y las ventanas, abiertas. Tengo en la cabeza dos artículos que empezaré a escribir.

- ¿Cuánto durará eso? -le pregunté.

-Cinco años, tal vez diez.

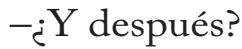

-Volveré.

El tercer ejemplo ocurrió hace poco. Un profesor de una gran universidad del Oeste llegó a Princeton a finales de diciembre pasado. Tenía en mente proseguir un trabajo con el profesor Morey (de la Universidad de Princeton). Pero Morey le sugirió que podría valer la pena ver a Panofsky y Swarzenski (del Instituto). Ahora está trabajando con los tres al mismo tiempo.

-Me quedaré - añadió- hasta octubre próximo.

-Verá que hace mucho calor en pleno verano -le dije.

-Estaré demasiado ocupado y muy feliz para notarlo.

La libertad no implica entonces el estancamiento, sino el peligro de trabajar en exceso. La esposa de un miembro inglés preguntó hace poco:

- ¿Todos trabajan hasta las dos de la mañana?

Hasta ahora el Instituto no tenido un edificio propio. En este momento los matemáticos son invitados de los matemáticos de Princeton en Fine Hall y algunos humanistas son invitados de los humanistas de Princeton en McCormick Hall; otros trabajan en lugares diseminados por la ciudad. Los economistas ocupan habitaciones en un hotel, el Princeton Inn. Mis propias dependencias están en un edificio de oficinas de la calle Nassau, donde trabajo entre tenderos, dentistas, abogados, quiroprácticos y grupos de académicos de Princeton que realizan una encuesta del gobierno local y un estudio de población. Los ladrillos y el mortero no son entonces tan esenciales, como lo demostró el presidente Gilman en Baltimore hace unos sesenta años. Pero echamos de menos el contacto informal entre unos y otros, $y$ estamos a punto de remediar este defecto construyendo un edificio 
proporcionado por los fundadores, que se llamará Fuld Hall. Pero la formalidad no irá más lejos. E1 Instituto debe seguir siendo pequeño, y se mantendrá firme en la convicción de que el grupo que lo compone quiere tiempo libre, seguridad, libertad frente a la organización y la rutina y, también, contactos informales con los académicos de la Universidad de Princeton y otros que de vez en cuando pueden ser atraídos a Princeton desde lugares distantes. Entre ellos, Niels Bohr vino de Copenhague, von Laue de Berlín, Levi Civita de Roma, André Weil de Estrasburgo, Dirac y G. H. Hardy de Cambridge, Pauli de Zúrich, Lemaître de Lovaina, Wade-Gery de Oxford, y estadounidenses de Harvard, Yale, Columbia, Cornell,Johns Hopkins, Chicago, California y otros centros de ilustración y conocimiento.

No nos hacemos promesas, pero albergamos la esperanza de que la libre búsqueda del conocimiento inútil tenga consecuencias en el futuro, así como en el pasado. Sin embargo, ni por un momento defendemos el Instituto por esa razón. Existe como un paraíso para estudiosos que, como los poetas y los músicos, se han ganado el derecho a hacer lo que les place y que logran más cuando se les permite obrar así. 